\title{
14
}

\section{Sustaining the Undergraduate Seminar: On the Importance of Modeling and Giving Guidelines}

\author{
Shelley Z. Reuter \\ Concordia University
}

Student-led discussion is a valuable means of involving students in the collaborative creation of knowledge. This activity becomes especially important in the seminar course where, either individually or in small groups, students lead their peers through a set of readings. Unfortunately, student-led discussions often focus more on summary than critical analysis, largely because seminar leaders, left to their own devices, do not know what a seminar should look like or how to lead one effectively. This chapter demonstrates that undergraduates can learn seminar leadership when provided with guidelines and opportunities to see the skill modeled.

tudent-led discussion is a valuable means of actively involving students in $S$ the democratic and collaborative creation of knowledge. It also encourages class citizenship and collective responsibility for the learning process. One type of course in which student-led discussion becomes especially vital is the seminar, where students, either individually or in small groups, are expected to lead their peers through a set of weekly readings.

Unfortunately, student-led discussions do not always unfold as professors imagine or hope, so seminars can sometimes be lackluster and aimless, focusing more on summary than on analysis and insight. Perhaps part of the problem is our assumption as professors that at the university level students will somehow just know how to lead a seminar. Though we understand the importance and value of a class discussion (Brookfield \& Preskill, 2005; 
Parker, 2001), we often forget that facilitating one is ultimately a form of teaching and requires skill that has to be cultivated.

To help revive our student-led seminars, we might turn to the instructional development literature. There we will find an abundance of materials on leading effective discussions (see, for example Davis, 1993, especially Chapter 3; McKeachie, 1994, especially Chapter 4), but for the most part these resources tend to be directed at graduate teaching assistants and new professors. In addition, their emphasis is more likely to be on how to give effective presentations (Taylor, 1992; Taylor \& Toews, 1999), how to structure (Knapper, Wilcox, \& Weisberg, 1996) and improve discussion (Cashin \& McKnight, 1986; Hollander, 2002), how to encourage participation (Reynolds \& Stevenson, 2003; Weimer, 1990), and how to ask good, discussable questions (Bonwell \& Eison, 1991; Rasmussen, 1984). Missing from these otherwise helpful resources are materials that concentrate on the unique context of a student-led seminar course-that is, information for professors who wish to show their students what a productive seminar looks like and how to lead one-though Steen, Bader, and Kubrin (1999) come close. This information is especially crucial for professors teaching upperlevel undergraduates and even new graduate students whose prior university courses have mostly, and in some cases entirely, been of the large, impersonal lecture-theater variety.

Building on my experiences with teaching fourth-year undergraduate seminars in Contemporary Theories, Feminist Theories, Sociology of Knowledge, and Sociology of Health and Medicine, I have developed a set of stepby-step guidelines that I give to and model for my students. A work in progress over the past several years, I have found modeling these guidelines to be extremely effective for cultivating the skill of seminar leadership and for realizing my goals for teaching seminars, namely 1 ) having students gain knowledge (content and theory) about the topic of the seminar, 2) developing students' competency in critical thinking about texts and especially in analyzing complex arguments that authors make, and 3 ) fostering the leadership skills required of a seminar leader, including the ability to engage in intellectual discussion. While all these goals involve skills that must be taught and learned, this chapter will focus in depth on the third objectivethe process of training students in seminar leadership.'

The following is a sample set of guidelines used in a Feminist Theories course in the 2005 winter term. I then describe the steps I take in reviewing the guidelines and modeling the seminar for students. The chapter ends with a brief analysis of potential pitfalls and solutions. 


\section{Step-by-Step Guidelines for Leading and Participating in Seminars}

Each student will, with my help, facilitate one seminar discussion. I have no expectation that you will be an "expert" but only that you generate discussion and guide the class to important things to think and talk about.

Think of the seminar as a group conversation that depends on everybody participating. This assignment is not meant to be scary or make anybody look foolish. Rather, it is intended to be part of a collective effort to help each of you gain a deeper understanding of the readings. This will, in turn, help you write stronger papers in this course. The seminars are also designed to allow you to take responsibility for your own learning. Doing so will make this course a much more rewarding experience for all of us.

\section{Steps for Seminar Leaders}

$\therefore$ Before Your Seminar

1) Plan your seminar in advance. Make an appointment to meet with me the week before your seminar so that I can make sure that what you've got planned is feasible and relevant and to give you an opportunity to ask any questions you may have. This meeting is worth $10 \%$ of your grade for this assignment.

2) Prepare an agenda for your seminar and make enough copies for everyone in the class, including me. This agenda should be a guide to what you intend to do in your seminar. It should not contain everything you plan to say, but only the key points/issues/questions you plan to address. It should not be more than one side of a page and should include a rough timeline for each component. This agenda will be included in the calculation of your overall grade for this assignment. A sample agenda will be provided.

\section{During Your Seminar}

I will lead the first two seminars. As I do so, we will discuss the assigned readings, but also the process of leading seminars. I will point out to you what I am doing as I lead the discussion as a way of modeling what I expect to see in your seminars. Briefly, your seminar should include the following: 
1) Synthesis. Provide a brief overview of the content of the assigned readings. Synthesize the main concepts, key points, and important issues raised by the readings. Be sure to address the similarities, differences, and connections among the assigned readings, focusing in particular on the argument each author is making.

2) Taking stock. Have everyone in the class share their impressions and questions about the readings. Two options (you may think of other methods): You could ask your classmates to write down the most important idea they got from the readings, and then have them share this with a partner, then the whole group. Or you could go around the circle and ask each person to give her or his impression of the readingsthat is, the arguments. The purpose of this step is to see if people have common perceptions of the readings and/or where the points of contention or difficulty lie. Allow time for discussion at this point.

\section{Remaining Elements, Not Necessarily in This Order}

1) Critique. Having heard your classmates' opinions, now do your own analysis of the arguments and ideas in the readings. Focus on the content and authors' assumptions rather than the form (i.e., language and style). Link the readings to ideas and issues raised in previous classes. Ask your classmates to evaluate which of the authors has a stronger argument, and why.

2) Reflection. Think about what you've learned from the readings, and what you took for granted before you read them. Think to yourselves, "This argument has changed the way I think about..." Compare your reflections with each other, and ask your classmates to share their reflections as well.

3) Questions for discussion. Ask your classmates to position themselves in relation to the arguments being made: "Would you align yourself with this belief? If not, what is your belief, and why?" Ask your classmates to consider the implications of the arguments: "If we take Author X's argument further, then it will mean that..." "This is a good idea because, or this idea is a problem because..." "If we accept Y's argument, then that means that $Z$ 's argument from three weeks ago is problematic because..." Ask any questions you can think of that might help your classmates think deeply about what is being argued in the readings. 


\section{Steps for Seminar Participants}

There are three main components to your role as seminar participant.

1) Reading. To optimize your participation, you must have completed the assigned readings. In a 400-level theory course, simply scanning the pages will be insufficient to sustain your contributions in class. At the end of each seminar, I will introduce the following week's topic, so you will need to study the readings and consider them in relation to this introduction.

2) Getting involved. You should join in the discussion whenever you have something to contribute that will help us move the discussion/debate forward. Whatever points you make should be relevant to and supported by specific references to the readings.

3) Reflection. What you can expect as a participant:

- You will be asked to comment on the readings.

- You may be asked to write a "minute paper" at the beginning of the seminar on "the most important idea I got from the articles for today is..." Or you may be asked to reflect in some other way, or to share your ideas for discussion. The more thoroughly you do the readings, the better the seminar discussion is likely to be.

- "Do unto others as you would have them do unto you." The success of a seminar is equally dependent on the seminar leadership and the seminar participation. If you want your classmates to be interested and actively involved when it's your turn to facilitate, you must be interested and actively involved in their seminars, too.

Note: It is acceptable from time to time to "pass" when asked a question, or to simply concur with an earlier point of view. However, be aware that repeatedly passing or agreeing with earlier comments without ever contributing anything new to the discussion may call into question your preparedness for the seminars and this in turn will impact your participation grade.

Ilook forward to our seminars! 


\section{Discussion}

However helpful these seminar guidelines may be on their own, their real potential to be useful to seminar leaders is contingent upon three key factors. First, the professor must introduce the seminar topic in the class before it is to be taken up. I use the last part of each three-hour class for this. Although not ideal, in courses broken up into two meetings per week, it is possible to stagger the classes so that the new topic is introduced in the second class of the week, giving students the weekend to prepare for the seminar the following week. Defining key concepts and outlining the background and main ideas of the material they will be seeing the following week helps student seminar leaders and participants focus their reading, which in turn places them in a better position to actually discuss the material during the seminar.

The second key component is meeting with the seminar leader(s) a few days before their class to review their plans and answer their questions. Students often have questions about the seminar process as well as the readings, especially in a theory course that assigns primary texts, and will need the opportunity for clarification. It is also important to be available by email or phone for any last-minute concerns.

The third and perhaps most important element is modeling the first two seminars. By modeling I mean the following: I go to the first class early and set up the desks in a circle, so the students get an initial sense on that first day of what a seminar physically looks like. After the preliminaries and housekeeping that normally take place in the first week of a course, I like to launch directly into the seminar format immediately in the second week. I tell students on that first day that I will be providing them with seminar guidelines and leading the first two seminars beginning the following week, and that they only need to come to the next class prepared with the readings done. In this first meeting I also introduce them to the topic of our first formal seminar.

When we meet for the second class, I come with enough copies of the guidelines and a sample corresponding agenda that outlines (in point form) the key ideas in the readings, points of critique and analysis, and questions for discussion (see Appendix 14.1). I give the students a few minutes to read through the guidelines and then I go over them in more detail. Once each step has been explained and any questions have been answered, we examine the assigned readings step-by-step, following both the guidelines and the agenda I have given them. I draw their attention to what I will be looking for in the agenda, since it will be part of the evaluation of their seminar: Is the handout helpful and easy to follow? Does it give the class a clear and brief outline of what will happen in the seminar? Then, as we go along, I say things like, 
"Okay, now I'm going to synthesize the readings. Note that I will be very brief, touching only on the highlights, and so on." I tell them that I assess how concise, focused, and on target their summary of the main points is. At this stage I also identify the central arguments of the readings and encourage them to focus on doing that in their summary.

Then we begin hearing from the other students. I will say, "Okay, let's take stock of people's sense of the readings" and ask them to write a minute paper about their initial impression of the arguments. Following this, I go around the circle and have students share what they wrote. (I point out that writing a minute paper is not a requirement of future seminars but an option to consider if the seminar leaders think it will be helpful for sparking discussion.) In this first seminar meeting, students do not yet know each other and giving them a moment to collect and write their thoughts seems to make it easier for them to then speak to the group. Discussion and reflection almost invariably take off from here, but if they are a less chatty group, I have discussion questions prepared (also included on the agenda).

Once students have expressed their own ideas about the readings, I summarize their comments, making links between them and adding any points of critique that may not have been raised but are important to consider. I also raise further questions for discussion and reflection as time permits. I conclude this first seminar by outlining for students the grading criteria (see Appendix 14.2) according to which their seminars (and participation) will be assessed, taking into consideration the relevance of the discussion and summary, the depth and creativity of the critical analysis, the kinds of discussion questions leaders raise, and the helpfulness of the agenda handout. I also emphasize that the leaders' role is to give the class things to think and talk about.

In short, I explain the steps outlined in the guidelines and model them at the same time. It is important to note that this first seminar will be unusually time-consuming and feel somewhat artificial due to its emphasis on the mechanics of leading a seminar. Thus it is necessary to limit the reading assignment for this first meeting to ensure that I have enough time to go through the different steps and to introduce the following week's topic. When I lead the second seminar, however, I do not spend time reviewing the guidelines again, except to point out which step I am at as I go along. At this point, the process always feels more natural because it focuses more on analysis and discussion of the assigned readings, and students are usually more at ease now that they have already experienced one seminar. In this second seminar I emphasize the critical analysis component, as well as the importance of making sure that the critical analysis is relevant to the readings, is creative, stimulates discussion, and explores the topic in depth. That said, the skill of seminar 
leadership is one that students develop over the course of the term. Modeling only two seminars does not magically transform them into expert facilitators, but it does give students much-needed direction and a place from which to begin from week to week.

\section{Potential Piffalls and Solutions}

One problem that may arise is that the seminar leaders may not come prepared or not come at all for their meeting prior to their seminar. To avoid this, I stipulate that not showing up or coming completely unprepared will result in a loss of 1 point out of a possible 10 seminar points. In four years of using these guidelines, I have never had to actually levy this penalty. In my experience students are happy for the opportunity to check in with me before they "present."

Another potential problem is that students may not do the readings for the seminar, thereby causing the leaders' efforts to fall flat. However, I do not penalize seminar leaders if their classmates come unprepared. Therefore, going around the room to solicit students' opinions in the first two seminars is a very important step in the modeling process. This strategy makes it clear to students very quickly that they cannot be invisible and that they need to come to class prepared to discuss the material. It is also important to establish a positive sense of community in the class to allow students to see how dependent they are on each other to pull their own weight. In reality, students rarely come with none of the readings done. If I see the class as a whole is struggling to do all of the readings, I will reduce them accordingly.

A third potential problem is that the student-led seminar can go astray, in spite of the guidelines. It should be clarified that these guidelines are not meant to eliminate work for the professor but simply to make it easier for the professor to do the work. That is, instructors must still take an active role in the classroom and be prepared to steer discussion when it veers off track. Even though students will lead the seminar, the professor must clarify what he or she wants the class to take away from the meeting (e.g., understanding the arguments and certain implications) and work collaboratively with the student leaders to ensure that the class meets this objective. Guiding the class in reading critically is important (see Rovinescu 2005), as is asking welltimed, pointed questions about the arguments being discussed.

A final potential problem is that providing these seminar guidelines may send the message to leaders that they are to take a methodical cookie-cutter approach that does not deviate from any of the steps outlined. I tell students 
that their seminar does not necessarily have to follow the steps exactly but that it must simply contain all the elements I have identified. I encourage them to be creative and to add their own touch, and some do. However, I prefer they do not do so to the point of disregarding the guidelines and leading an uninspired discussion.

\section{Conclusion}

Since I began taking the time to actually tell and show my students how a seminar is conducted, the quality of discussion (and in turn students' writing) in these courses has improved significantly and has helped reduce students' anxiety about their role as seminar leaders. As one student wrote in a recent university course evaluation, this was "good preparation for future seminar classes," and as another put it, "I appreciated learning the skills of directing a seminar in an environment [in which] I felt safe/open to questioning and ideas." I recently solicited feedback about the guidelines and modeling specifically from students in my Sociology of Knowledge course ( $\mathrm{n}$ $=15$ ) and received positive appraisals: A score of 4.2 out of 5 on "The seminar guidelines will help me prepare to lead a seminar ..."; 4.4 on "The first two seminars gave me a good idea of what a seminar should look like..."; and 4.3 on "I have a better sense of what is expected of me because of the seminar guidelines..."

Seminars are obviously much more effective and enjoyable when students come prepared and the class has a coherent plan of action. The steps outlined in this chapter help students develop such a plan. In addition, these guidelines allow both the students and me to focus on the content of their seminar rather than the structure-students in their preparation and analysis, and me in my assessment. When seminar leaders can go beyond merely summarizing the assigned readings to facilitating analysis, critique, and reflection, then the conditions are in place for all students to develop insight into the readings that they might not otherwise have. In turn, students' writing about the materials improves and deepens. The benefits of a productive student-led seminar are irrefutable, but they can elude us if we fail to show students exactly what a good seminar leader does. 


\section{Acknowledgments}

I wish to thank Katherine Lagrandeur, Susan Wilcox, and the anonymous reviewers for their encouragement and suggestions. Laura DesRosiers was instrumental in doing the library research for this chapter. Eileen Bragg helped me to develop these guidelines and convinced me to share them in an instructional development workshop that we co-facilitated at Memorial University in 2003; her input, along with feedback from the workshop participants, played a crucial role in bringing this chapter to fruition. Finally, I am grateful to all my seminar students over the years for patiently, if unwittingly, helping me learn how best to help them learn.

\section{Endnotes}

1) Instructors must also take steps to support other goals. For example, in support of the goal of learning content, I introduce students to each topic the week before each seminar (see the "Discussion" section). I also spend time with students working on the identification and analysis of arguments by 1) examining a critical reading handout (see Rovinescu, 2005) at the beginning of the term, 2) providing students with questions to think about for the following week's seminar, and 3) giving a reaction paper assignment where students identify and react to some aspect(s) of the arguments being made. To support this assignment we read and compare two sample reaction papers-an $\mathrm{A}$ and a $\mathrm{C}$ paper-within the first two classes to illustrate the difference between summary and rigorous analysis (e.g., strengths, limits, links between, and implications of the arguments being made). Additionally, when modeling the seminar, I zero in on the main arguments of the assigned readings and lead the students through the process of critique. Taken together, these measures are useful for helping students learn to identify arguments and discuss them, both orally and in written form.

\section{References}

Bonwell, C. C., \& Eison, J. A. (1991). Active learning: Creating excitement in the classroom. Washington, DC: George Washington University.

Brookfield, S. D., \& Preskill, S. (2005). Discussion as a way of teaching: Tools and techniques for democratic classrooms (2nd ed.). San Francisco, CA: Jossey-Bass.

Cashin, W. E., \& McKnight, P. C. (1986). Improving discussions (Idea Paper No. 15). Manhattan, KS: Kansas State University, Center for Faculty Evaluation and Development. 
Davis, B. G. (1993). Tools for teaching. San Francisco, CA: Jossey-Bass.

Hollander, J. A. (2002, July). Learning to discuss: Strategies for improving the quality of class discussion. Teaching Sociology, 30(3), 317-327.

Knapper, C., Wilcox, S., \& Weisberg, M. (1996). Teaching students more: Discussion with more students. Ontario, Canada: Queen's University, Instructional Development Centre.

McKeachie, W. J. (1994). McKeachie's teaching tips: Strategies, research, and theory for college and university teachers (9th ed.). Lexington, MA: D.C. Heath.

Parker, W. C. (2001, March). Classroom discussion: Models for leading seminars and deliberations. Social Education, 65(2), 111-115.

Rasmussen, R. V. (1984). Practical discussion techniques for instructors. AACE Journal, 12(2), 38-47.

Reynolds, G., with Stevenson, K. (2003). Leading discussions: What every student (and lecturer) needs to know! Retrieved June 18, 2006, from the Staffordshire University, Department of Sociology and Crime, Deviance, and Society web site: www.staffs.ac.uk/schools/humanities_and_soc_sciences/sociology/leaddiss.htm

Rovinescu, O. (2005). Critical reading guide. Quebec, Canada: Concordia University, Centre for Teaching and Learning Services.

Steen, S., Bader, C., \& Kubrin, C. (1999, April). Rethinking the graduate seminar. Teaching Sociology, 27(2), 167-173.

Taylor, K. L., \& Toews, S. V. M. (1999, July). Effective presentations: How can we learn from the experts? Medical Tencher, 21(4), 409-414.

Taylor, P. (1992). Improving graduate student seminar presentations through training. Teaching of Psychology, 19(4), 236-238.

Weimer, M. (1990). Successful participation strategies. In M. Weimer \& R. A. Neff (Eds.), Teaching college: Collected readings for the new instructor (pp. 95-96). Madison, WI: Magna. 


\section{Appendix 14.1}

\section{Sample Agenda}

Liberal Feminism

1) Synthesis (10-15 minutes)

\section{Betty Friedan}

- Housewives in despair, need more in their lives

- Equal access to college educations and full-time paid work

Joyce Trebilcot

- There shouldn't be separate sex roles based on psychological differences between women and men

\section{Kathleen Jones}

- Liberal feminist argument for inclusion of women in military is contradictory, shortsighted

- Inclusion of women in military will not change patriarchal values, nor will it mean equality for civilian women

- Women need access to positions of power; only then can women redefine what it is to be a full "citizen"

2) Taking stock (20-25 minutes)

- Everyone's impressions, most important ideas, discussion

3) Critique and analysis (3-5 minutes)

- Inequality and privilege

- Affirmation of patriarchal values

- Affirmation of capitalism

4) Reflect and discuss (remaining time)

- In what respects and to what extent does liberal feminism challenge the social order (or not)?

- Does liberal feminism continue to serve any purpose today?

- How do we account for the recent craze over "housewife shows" (Desperate Housewives, Wife Swap, etc.)?

- What does liberal feminism, especially Friedan's, mean for men today-that is, "househusbands"?

Are these men headed down the same road that Friedan describes? 
Appendix 14.2

\section{Grading Criteria: Feminist Theories}

\section{Grading Criteria for Seminar Leadership}

$\begin{aligned} & \text { Outstanding } \\
& \text { A }(80+)\end{aligned} \quad \mathrm{C}(60-69)$
\begin{tabular}{|l|l|}
\hline Discussion is relevant to the week's readings & Discussion has little relevance \\
\hline Topic is explored in depth & Superficial treatment of topic \\
\hline $\begin{array}{l}\text { Takes off from and builds on the readings, } \\
\text { and external materials are used when relevant }\end{array}$ & Is strictly a summary of the readings \\
\hline $\begin{array}{l}\text { Engaging, creative, and encourages class dis- } \\
\text { cussion; raises new and interesting questions; } \\
\text { gives group things to think and talk about }\end{array}$ & $\begin{array}{l}\text { Does not encourage or enable class } \\
\text { discussion }\end{array}$ \\
\hline $\begin{array}{l}\text { Handout is helpful, easy to follow, gives class } \\
\text { a loose outline of what will happen }\end{array}$ & $\begin{array}{l}\text { Handout has too much irrelevant informa- } \\
\text { tion and doesn't help the group keep up }\end{array}$ \\
\hline
\end{tabular}

Remember: You don't have to be the "expert" on feminist theory, nor do you have to understand absolutely everything in the readings. But you do have to lead us in what we'll talk about. (It's okay to ask that we go over specific difficult bits!)

\section{Grading Criteria for Preparation and Involvement in Discussion}

- Attendance, coming to class on time

- Preparation for seminar (i.e., do the readings, come to class prepared to discuss the material)

- The quality of your contribution to the group; the extent to which you supply ideas that move others' learning forward

- Receptiveness to others' ideas and the extent to which you actively listen to what others have to say

- Your part in facilitating a community of learning 